\title{
Positive association of heparanase expression with tumor invasion and lymphatic metastasis in gastric carcinoma
}

\author{
Zhenning Wang ${ }^{1,2}$, Huimian $\mathrm{Xu}^{2}$, Li Jiang ${ }^{1}$, Xin Zhou ${ }^{2}$, Chong $\mathrm{Lu}^{2}$ and Xue Zhang ${ }^{1,3}$ \\ ${ }^{1}$ The Research Center for Medical Genomics and MOH Key Laboratory of Cell Biology; ${ }^{2}$ Department of \\ Surgical Oncology, the First Hospital of China Medical University, Shenyang, PR China and ${ }^{3}$ Department of \\ Medical Genetics and National Key Laboratory of Medical Molecular Biology, Institute of Basic Medical \\ Sciences, Chinese Academy of Medical Sciences and Peking Union Medical College, Beijing, PR China
}

\begin{abstract}
Tumor invasion and metastasis are the most common causes of death in gastric carcinoma. Human heparanase influences tumor invasiveness and angiogenesis. Analysis of its expression in gastric carcinoma has been hindered by our inability to procure pure cancer cells from heterogeneous tissue. In the present study, we analyzed heparanase expression in human primary and metastatic gastric carcinoma cells as well as in paired normal gastric epithelial cells by laser capture microdissection coupled with reverse transcriptionpolymerase chain reaction (RT-PCR). Tumor tissues, metastatic lymph nodes, and apparently uninvolved normal gastric tissues were collected from 30 patients who had undergone gastrectomy with radical lymph node dissection for gastric carcinoma without preoperative treatment. Bulk tissues and laser capture microdissected cell groups were separately subjected to RT-PCR analysis with heparanase-specific primers. For bulk tissues, heparanase-specific transcripts were detectable in all primary tumor tissues, metastatic lymph nodes, and almost all matching normal tissues. RT-PCR analysis after laser capture microdissection showed no detectable heparanase expression in matching normal epithelial cell groups. Of the laser capture microdissected primary gastric carcinoma cells, 47\% (14/30) were heparanase positive. Expression was closely associated with greater tumor invasiveness, including Borrmann gross type and depth of wall infiltration. For metastatic cell groups dissected from lymph nodes, $95 \%$ showed clear heparanase expression. Furthermore, the extent of lymphatic spread was directly correlated to heparanase expression at the primary site. In conclusion, laser capture microdissection coupled with RT-PCR is a reliable approach for molecular analysis of heparanase expression in gastric carcinoma. Heparanase may facilitate invasion and metastasis of gastric carcinoma cells.
\end{abstract}

Modern Pathology (2005) 18, 205-211, advance online publication, 8 October 2004; doi:10.1038/modpathol.3800282

Keywords: gastric carcinoma; laser capture microdissection; lymphatic metastasis; heparanase expression

It is generally accepted that the invasion of the basement membrane and extracellular matrix is one of the critical steps for cancer cell metastasis. ${ }^{1}$ Heparan sulfate proteoglycans, composed of a protein core covalently linked to heparan sulfate side-chains, represent a principal component of the extracellular matrix and, in particular, basement membranes. Cell surface heparan sulfate can also serve as coreceptors, along with the other cell surface molecules, to form functional receptor

Correspondence: Dr Xue Zhang, MD, PhD, The Research Center for Medical Genomics, China Medical University, No. 92, North 2nd Road., Heping Dist., Shenyang 110001, PR China.

E-mail: xzhang@mail.cmu.edu.cn

Received 28 April 2004; revised 9 August 2004; accepted 10

August 2004; published online 8 October 2004 complexes that facilitate signal transduction. ${ }^{2}$ Furthermore, heparan sulfate chains bind a large number of bioactive molecules and regulate their availability and function. These include growth factors, chemokines, cytokines, and enzymes that are essential for angiogenesis, cell adhesion, and locomotion. ${ }^{3}$ Accordingly, enzymatic degradation of heparan sulfate may play a critical role in cancer cell invasion and metastasis. Heparanase is an endoglycosidase that cleaves heparan sulfate side chains of heparan sulfate proteoglycans at a limited number of sites, thus facilitating disassembly of the extracellular matrix and enhancing cell invasion. At the same time, heparan sulfate degradation also results in the release of bound bioactive molecules from extracellular matrix depots, and makes them available. Heparanase mRNA is strongly expressed in 
metastatic cancer cell lines. However, in vivo analysis of its expression in cancer patients has been hindered by our inability to directly procure pure populations of cancer cells from complex heterogeneous tissue, especially from the ubiquitously distributed lymphatic-derived cells that primarily express heparanase.

Laser capture microdissection is a technique that allows for the rapid, reliable, and accurate procurement of cells from specific microscopic regions of tissue sections under direct visualization. ${ }^{4}$ With it we can evaluate the role heparanase plays in the invasive and metastatic potential of pure populations of cancer cells in their native tissue environment. In this study, we used laser capture microdissection to capture primary and metastatic gastric cancer cells and tried to find out whether heparanase expression was associated with the degree of tumor invasiveness and metastasis or not.

\section{Materials and methods}

\section{Patients}

In all, 30 patients (25 males and five females) who underwent gastrectomy with lymph node dissection for gastric carcinoma at the China Medical University, Shenyang, between March and September of 2000 were included in the study. None of the patients had received preoperative chemotherapy. The patients ranged in age from 33 to 78 years (median, 57 years). Routinely, the resected specimens were histologically examined by hematoxylin-eosin (H\&E) staining according to the general rules of the classification of gastric carcinoma suggested by the Japanese Research Society for Gastric Cancer. ${ }^{5}$ The Borrmann gross type, the Lauren histological classification, the Ming classification of growth pattern, grade of differentiation, and levels of lymph node metastasis were obtained from the operative records and the pathology reports. The pT classification representing the depth of wall invasion and the $\mathrm{pN}$ classification representing the extent of regional lymph node metastasis were performed using standard criteria of 5th TNM staging system. ${ }^{6}$ The total lymph node number collected from the tissue was 15 or more for a reliable pN classification. Three patients with benign gastric ulcer underwent surgery in the same period were also included as a control group with informed consent.

\section{Tissue Samples}

The tumor tissue, lymph nodes, and apparently uninvolved normal tissue were collected from each patient immediately after surgical removal, snapfrozen in liquid nitrogen, and kept at $-80^{\circ} \mathrm{C}$ until use. Parts of bulk tissue (50-100 mg each) were directly used for RNA isolation, and the remaining was embedded in OCT medium for subsequent laser capture microdissection harvest. Frozen sections were then cut at $8 \mu \mathrm{m}$ with a cryostat and mounted on uncoated glass slides, and one section stained with $\mathrm{H} \& \mathrm{E}$ was used to histopathologically confirm the diagnosis. The slides were immediately stored at $-80^{\circ} \mathrm{C}$ for several weeks. In order to exclude the areas of necrosis, tumor tissues from all patients were selected from the most viable areas of tumors. The lymph nodes were obtained according to the standardized protocol. Pathologists documented the number of removed and positive lymph nodes for various stations. Matching uninvolved gastric mucosa specimens were obtained from the tissue at a distance of more than $10 \mathrm{~cm}$ from the tumor edge.

\section{RT-PCR of Bulk Tissues}

Total RNA was isolated using TRIzOL Reagent (Life Technologies, Inc.) from 50 to $100 \mathrm{mg}$ of tumor, metastatic lymph node, and normal gastric mucosa tissue, respectively, according to the recommendations of the manufacturer. After DNase I treatment, first-strand cDNA was synthesized by priming $1 \mu \mathrm{g}$ of total RNA with random hexamers in a $20 \mu \mathrm{l}$ reaction mixture containing $2 \mu \mathrm{l}$ of $10 \times \mathrm{RT}$ buffer, $4 \mu \mathrm{l}$ of $25 \mathrm{mM} \mathrm{MgCl}_{2}, 1 \mu \mathrm{l}$ of $10 \mathrm{mM} \mathrm{dNTP} \mathrm{mix,} 2 \mu \mathrm{l}$ of $0.1 \mathrm{M} \mathrm{DTT}, 1 \mu \mathrm{l}$ of RNasin $(40 \mathrm{U} / \mu \mathrm{l})$ (Promega, Madison, WI, USA), and $200 \mathrm{U}$ of SuperScript ${ }^{\mathrm{TM}}$ II RT (Life Technologies, Inc.) After incubation at $25^{\circ} \mathrm{C}$ for $10 \mathrm{~min}$, the reaction was performed at $42^{\circ} \mathrm{C}$ for $50 \mathrm{~min}$. The reverse transcriptase was inactivated at $70^{\circ} \mathrm{C}$ for $15 \mathrm{~min}$. PCR amplification with specific primers was performed in a final reaction volume of $20 \mu \mathrm{l}$ containing $1 \times$ PCR buffer, $200 \mu \mathrm{M}$ each $\mathrm{dNTP}$, $0.5 \mu \mathrm{m}$ each primer, $0.5 \mathrm{U}$ of Taq polymerase (Takara Biochemicals, Japan), and $2 \mu \mathrm{l}$ of RT product. Programmable temperature cycling (UNO II, Biometra, Germany) was performed using the following profiles: $95^{\circ} \mathrm{C}$ for $1 \mathrm{~min}$, followed by 35 cycles of $94^{\circ} \mathrm{C}$ for $30 \mathrm{~s}, 55^{\circ} \mathrm{C}$ for $30 \mathrm{~s}$ and $72^{\circ} \mathrm{C}$ for $45 \mathrm{~s}$. After the last cycle, an elongation step was extended by $10 \mathrm{~min}$ at $72^{\circ} \mathrm{C}$. For each set of PCR, parallel reactions with human genomic DNA from peripheral blood were performed to test for genomic DNA contamination, and double-distilled water instead of cDNA template was also included as a negative control to assure the quality of the PCR. A $10 \mu \mathrm{l}$ aliquot of the PCR product underwent electrophoresis on $2 \%$ agarose gel stained with ethidium bromide and was visualized under a UV transilluminator. The following primers were used: (a) heparanase, forward primer 5'-CACAAACA CTGACAATCCAAGG-3', and reverse primer 5'CCATTGAGTTGGACAGATTTGG-3' (PCR product, 180bp); (b) glyceraldehyde-3-phosphate dehydrogenase (G3PDH), forward primer 5'-AGGGGTCTA CATGGCAACTG-3', and reverse primer 5'-CGAC CACTTTGTCAAGCTCA-3' (PCR product, $227 \mathrm{bp}$ ). 


\section{Laser Capture Microdissection}

OCT-embedded blocks of frozen tissue were serially cut. For each case, the first section was stained with $\mathrm{H} \& \mathrm{E}$ for routine histological analysis, and digitalized. The following serial section was stained with $\mathrm{H} \& \mathrm{E}$ according to the standard protocol recommended by NIH, ${ }^{7}$ and was subjected to laser capture microdissection using an LM200 system (Olympus, Japan/Arcturus Engineering Inc., USA). The parameters included a laser diameter of $7.5 \mu \mathrm{m}$, with laser power of $60 \mathrm{~mW}$. In all, 5000 laser pulse discharges per specimen were used to 'capture' approximately 10000 morphologically normal gastric epithelial cells, and primary and metastatic gastric carcinoma cells from each case. Each population was estimated to be $>95 \%$ 'homogeneous' as determined by microscopic visualization of the captured cell. The caps with the captured cells were then fitted onto $0.5 \mathrm{ml}$ microcentrifuge tubes containing $200 \mu \mathrm{l}$ TRIzOL Reagent. Caps briefly placed onto the section without laser activation were used as negative control.

\section{RNA Extraction from Laser Capture Microdissected Cells}

Total RNA from each population of laser-captured cells was independently extracted using TRIzOL Reagent by means of a modification of the RNA microisolation protocol recommended by the manufacturer. Briefly, tubes containing collected cells and TRIzOL Reagent were inverted and allowed to settle at room temperature for $30 \mathrm{~min}$, and then $0.5 \mu \mathrm{l}$ glycogen $(20 \mu \mathrm{g} / \mu \mathrm{l})$ carrier and $40 \mu \mathrm{l}$ chloroform was added to each tube. Tubes were shaken vigorously by hand for $15 \mathrm{~s}$ and incubated at room temperature for $2 \mathrm{~min}$. The samples were centrifuged at $11000 \mathrm{rpm}$ for $15 \mathrm{~min}$ at $4^{\circ} \mathrm{C}$. The aqueous layer was transferred to a fresh $0.5 \mathrm{ml}$ tube; $100 \mu \mathrm{l}$ isopropanol was added and precipitated at $-70^{\circ} \mathrm{C}$ for $1 \mathrm{~h}$. After recentrifuging at $11000 \mathrm{rpm}$ for $10 \mathrm{~min}$ at $4{ }^{\circ} \mathrm{C}$, the pellet was then washed in $200 \mu \mathrm{l}$ of $75 \%$ ethanol and resuspended in $7 \mu \mathrm{l}$ diethylpyrocarbonate-treated RNase-free water.

\section{RT-PCR of Microdissected Cells}

For RT-PCR analysis of the laser capture microdissected cells, first-strand cDNA was prepared from total RNA by using a first-strand synthesis kit (Life Technologies Inc.). A Volume of $7 \mu \mathrm{l}$ of total RNA isolated from approximately 10000 cells were mixed with $1 \mu \mathrm{l}$ of oligo- $(\mathrm{dT})_{12-18}$ primer, $1 \mu \mathrm{l}$ of random hexamers primer $\left(\mathrm{N}_{6}\right)$, and $1 \mu \mathrm{l}$ of $10 \mathrm{mM}$ dNTPs in a total volume of $10 \mu \mathrm{l}$. They were heat denaturated at $65^{\circ} \mathrm{C}$ for $5 \mathrm{~min}$, and then chilled in ice. Measure of $4 \mu \mathrm{l}$ of $5 \times$ first-strand reaction buffer, $2 \mu \mathrm{l}$ of $0.1 \mathrm{M}$ DTT, $2 \mu \mathrm{l}$ of $25 \mathrm{mM} \mathrm{MgCl}_{2}, 1 \mu \mathrm{l}$ of $\operatorname{RNasin}(40 \mathrm{U} / \mu \mathrm{l})$ and $1 \mu \mathrm{l}$ of SuperScript $^{\mathrm{TM}}$ II
$(200 \mathrm{U} / \mu \mathrm{l})$ were added and incubated at $25^{\circ} \mathrm{C}$ for $10 \mathrm{~min}$, followed by incubation at $42^{\circ} \mathrm{C}$ for $50 \mathrm{~min}$ for first-strand synthesis. The reverse transcriptase was inactivated at $70^{\circ} \mathrm{C}$ for $15 \mathrm{~min}$. Then, PCR amplification of 40 cycles with $2 \mu \mathrm{l}$ of RT product as template was performed as described above.

\section{Statistical Analysis}

Statistical comparisons for significance between nominal variables were evaluated by the $\chi^{2}$ test and the Fisher's exact probability test. Statistical analyses were performed using SPSS10.0 computer software and $P$-values of less than 0.05 were considered to be statistically significant.

\section{Results}

\section{Heparanase Expression in Bulk Tissue}

To detect heparanase mRNA expression by RT-PCR, a pair of specific primers was designed and synthesized. RT-PCR analysis was first performed using total RNA directly isolated from bulk tissue samples. Heparanase-specific transcripts represented by a specific amplified fragment of $180 \mathrm{bp}$ were detectable in $93 \%(28 / 30)$ of the matching normal gastric tissues, $100 \%$ (30/30) of the primary tumor tissues, and $100 \%$ (30/30) of the metastatic lymph nodes, respectively.

\section{Heparanase Expression in Microdissected Gastric Epithelial and Cancer Cells}

Laser capture microdissection with microscopic observation allowed us to precisely sample the gastric epithelial and cancer cells (Figure 1a). To assess the quality of the extracted RNA from laser capture microdissected cells, RT-PCR was first performed for the housekeeping gene G3PDH. The use of approximately 10000 cells produced consistent and satisfactory signals. Heparanase expression in laser capture microdissected cells was then reexamined by RT-PCR analysis (Figure 1b, c). In all, $47 \%(14 / 30)$ of the primary gastric carcinoma cell groups were shown to have detectable heparanase expression. Furthermore, 95\% (19/20) of the metastatic gastric carcinoma cell groups from lymph nodes evidenced clear expression, comparable to that in positive primary cancers. However, none of the matching uninvolved epithelial cell groups and normal epithelial cell groups from benign control patients had detectable heparanase expression.

\section{Association of Heparanase Expression with Tumor Invasion and Metastasis}

After re-examination in the laser capture microdissected cancer cells, heparanase expression in 


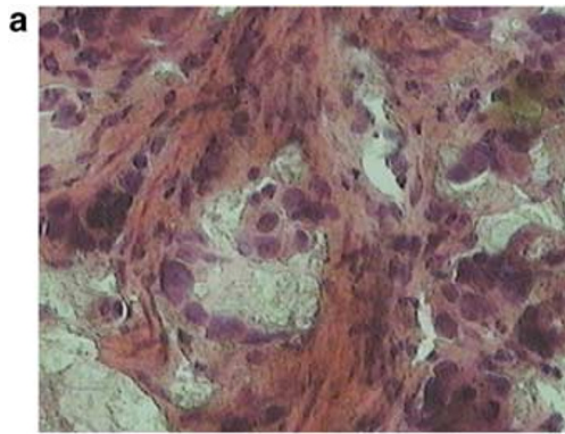

\section{b}

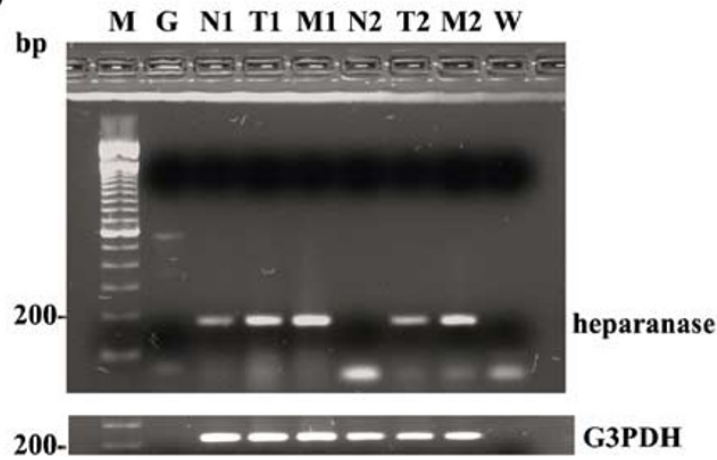

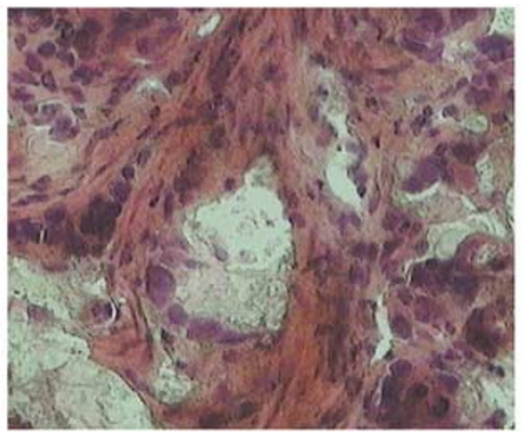

C

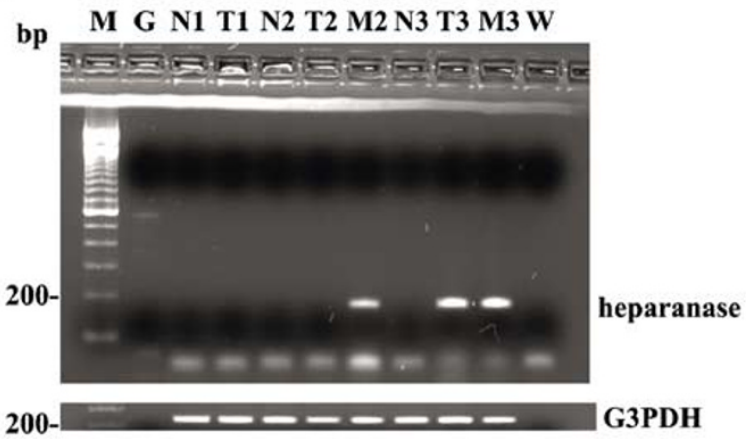

Figure 1 (a) Microdissection of cells from gastric carcinoma before (left) and after (middle) laser capture microdissection. Selected carcinoma cells were isolated on the cap (right). H\&E $\times 200$. (b) Comparison of heparanase expression in bulk tissues (lanes 3-5) and laser capture microdissected cells (lanes 6-8). (c) Representative RT-PCR results in laser capture microdissected cells. Lanes 3-4 for a patient without lymphatic metastasis; lanes 5-7 for a patient with nodal metastasis number less than 7 and localized in group 1; lanes 810 for a patient with extensive lymphatic metastasis. Shown are (G) genomic DNA from human peripheral blood, (N) morphologically normal gastric mucosa, (T) tumor tissue, (M) metastastic lymph node, (W) water as negative control.

primary tumors was associated with a higher degree of tumor invasiveness. The expression rate in advanced carcinomas at stages $\mathrm{T}_{3-4}$ was significantly higher than that seen in the earlier $\mathrm{T}_{1-2}$ stages $(P<0.05)$. Overall, 93\% $(13 / 14)$ of heparanasepositive primary tumors were classified as Borrmann III $(n=8)$ or Borrmann IV $(n=5)$. The percentage was significantly higher than those for heparanase-negative cases $(P<0.05)$. However, we noted no significant correlation between heparanase expression in primary gastric carcinoma cells and the Lauren histological classification or the Ming classification of growth pattern or grade of differentiation (Table 1).

Heparanase expression in primary gastric carcinoma cells was also related to the metastatic behavior of tumors (Table 2). The expression rate $(65 \%, 13 / 20)$ in patients with lymph node metastasis was significantly higher $(10 \%, 1 / 10)$ than in those without metastasis $(P<0.01)$. Furthermore, heparanase expression was frequently detected in cases with metastasis of more lymph nodes. Of the 20 patients with histologically evident lymph node metastases, seven were classified as $\mathrm{pN}_{1}$, with metastasis in one to six regional nodes, according to the TNM staging system. Only one showed detectable heparanase expression in the laser capture microdissected primary gastric carcinoma cells. Conversely, heparanase expression was significantly
Table 1 Heparanase expressions in laser capture microdissected primary gastric carcinoma

\begin{tabular}{lccc}
\hline Variant & $\begin{array}{c}\text { Heparanase } \\
\text { expression }\end{array}$ & Significance \\
\cline { 2 - 3 } & Positive & Negative & \\
\hline Gross type & 1 & 7 & $P<0.05$ \\
$\quad$ Borrmann I+II & 13 & 9 & \\
$\quad$ Borrmann III+IV & & & \\
Depth of invasion & 1 & 9 & $P<0.01$ \\
$\mathrm{pT}_{1}+\mathrm{pT}_{2}$ & 13 & 7 & \\
$\quad \mathrm{pT}_{3}+\mathrm{pT}_{4}$ & & & \\
Differentiation & 2 & 6 & $\mathrm{NS}$ \\
$\quad$ Well and moderate & 12 & 10 & \\
$\quad$ Poor and undifferentiated & & & \\
Lauren classification & 10 & 15 & $\mathrm{NS}$ \\
$\quad$ Intestinal type & 4 & 1 & \\
$\quad$ Diffuse type & & & \\
Ming growth pattern & 6 & 6 & $\mathrm{NS}$ \\
$\quad$ Expanding & 8 & 10 & \\
$\quad$ Infiltrative & & & \\
\hline
\end{tabular}

${ }^{\text {a }} P$-value was estimated by the Fisher's exact test.

${ }^{\mathrm{b}} \mathrm{NS}$, not significant.

more frequent in cancer cells captured from primary tumors with metastasis in more than six regional nodes $(P<0.01)$. When the Japanese classification was used, five patients could be defined as $\mathrm{N}_{1}$ 
Table 2 Heparanase expressions in relation to lymph node metastasis

\begin{tabular}{lccc}
\hline Status & \multicolumn{2}{c}{ Heparanase } & \multirow{2}{*}{ Significance $^{\mathrm{a}}$} \\
\cline { 2 - 3 } & Positive & Negative & \\
\hline $\begin{array}{l}\text { Lymph node metastasis } \\
\quad \text { Absent }\end{array}$ & 1 & 9 & $P<0.01$ \\
$\quad$ Present & 13 & 7 & \\
$p N$ classification of TNM & & & \\
$\mathrm{pN}_{1}$ & 1 & 6 & $P<0.01$ \\
$\mathrm{pN}_{2}+\mathrm{pN}_{3}$ & 12 & 1 & \\
$N$ classification of Japan & & & \\
$\mathrm{N}_{1}$ & 0 & 5 & $P<0.01$ \\
$\mathrm{~N}_{2}+\mathrm{N}_{3}$ & 13 & 2 & \\
\hline
\end{tabular}

${ }^{\mathrm{a}} P$-value was estimated by the Fisher's exact test.

(metastasis localized at Group 1 lymph nodes). None of these had a detectable heparanase expression in laser capture microdissected primary cancer cells. However, eight of 10 cases at $\mathrm{N}_{2}$ (metastasis to Group 2 lymph nodes) and five of five cases at $\mathrm{N}_{3}$ (metastasis to Group 3 lymph nodes) were positive for heparanase expression in primary cancer cells.

\section{Discussion}

The metastatic potential of tumor cells is related to their heparanase content. ${ }^{8}$ For tumor cells to invade surrounding tissues and metastasize to distant organs, degradation of the extracellular matrix and basement membrane is essential. Thus, a key aspect of tumor cell invasion is likely the cleavage of heparan sulfate molecules by heparanase, a supposition that is now confirmed from investigations of in vitro human metastatic cancer cell lines. ${ }^{9}$ Ascertaining the role of heparanase in in vivo metastasis was stymied by the heterogeneity of the tissue. In our study, direct RT-PCR from bulk tissue showed that almost all of the matching normal gastric tissue had detectable heparanase expression. Inoue et al, ${ }^{10}$ who analyzed 71 samples of gastric carcinomas by RT-PCR, also found the ubiquitous expression of heparanase in normal tissue, and concluded that the clinical and pathological impact of heparanase on gastric carcinoma progression was low compared with other proteinases. This deviation could be ascribed to the fact that heparanase mRNA widely existed in stromal and inflammatory cells, such as neutrophils, lymphocytes, and endothelial cells. So we performed RT-PCR with laser capture microdissection to investigate heparanase gene expression in primary, metastatic cancer cells, and paired normal epithelial cells. Heparanase expression is absent in all laser capture microdissected normal epithelial cells; bolstering our hypothesis that contamination by other cells in bulk tissue may be the reason, prior investigators reported pseudopositive results for heparanase gene expression. Some reports have confirmed that no positive labeling of heparanase expression was identified in normal epithelial cells, while significant staining was observed in stroma by means of in situ hybridization and immunostaining. ${ }^{11,12}$

Our results show that heparanase mRNA was detectable in $47 \%$ of the laser capture microdissected primary gastric carcinoma cells and its expression was closely associated with a higher degree of tumor invasiveness. In all, 93\% of heparanase-positive primary cancers were classified as Borrmann III or IV. There was also a correlation between the depth of invasion and heparanase expression; tumors penetrating the serosa had a significantly higher rate of expression than those localized in the stomach wall. In previous studies, it was demonstrated that both the macroscopic appearance and depth of invasion are independent prognostic indicators in gastric carcinoma. ${ }^{13}$ Thus, the expression of heparanase in gastric carcinoma may correlate with a more aggressive course.

Heparanase expression was also directly correlated with tumor metastasis. Of metastatic cancer cell groups dissected from lymph nodes, $95 \%$ had a clear expression of heparanase, comparable to expression rates in positive primary cancers. This confirmed earlier findings that heparanase mRNA is highly expressed in metastatic rat and human breast cancer cell lines in vitro, whereas the nonmetastatic variants express little or no heparanase mRNA. ${ }^{14-16}$ The incidence of heparanase expression in primary cancers was significantly higher in patients with lymph node metastases than those without metastases. Two of the essential processes required for metastasis are angiogenesis and tumor cell invasion of the basement membrane and extracellular matrix. Heparanase expressed by gastric carcinoma cells may facilitate the deterioration of extracellular matrix and basement membrane barriers by cleavage of heparan sulfate chains. Heparanase may also contribute to angiogenesis by release and activation of various heparan sulfate-binding growth factors. ${ }^{17}$ Combined, the findings of high expression rate in primary gastric carcinoma with lymph node metastasis suggest that heparanase enzymatic activity might be involved in the detachment and escape of the tumor cells from the primary site. Moreover, gastric carcinoma cells that have metastasized into lymph node showed a higher expression rate, suggesting that its presence at the metastatic site might be a prerequisite for lymphatic metastasis of cancer cells.

The extent of lymphatic spread of gastric carcinoma is decisive in choosing surgical lymphadenectomy and in estimating the prognosis of individual patients. The Japanese classification of lymphatic spread is based on the anatomic localization of the lymph nodes in relation to the localization of the 
primary tumor. The $\mathrm{pN}$ classification of the current TNM staging system is based on the number of involved regional lymph nodes. Therefore, we investigated whether there was a direct correlation between heparanase expression at the primary site and the extent of lymphatic spread in gastric carcinoma. Negative heparanase expression was significantly more frequent in primary tumors with metastasis in less than seven regional nodes or those with metastasis localized in Group 1 lymph nodes. This finding may be ascribable to the limited ability of cancer cells with low metastatic potential to produce heparanase. Another reason may be related to the functional heterogeneity of cancer cells at the primary site. A tumor's low metastatic potential results in a low proportion of the subpopulation of cancer cells producing heparanase at the primary site, and lower heparanase expression. However, whether heparanase expression can be used as a potential marker of metastatic extent will require further studies with large samples.

Some reports have demonstrated that heparanase activity can be blocked with various nonanticoagulant heparin derivatives and related sulfated negatively charged molecules. ${ }^{18-21}$ These factors that decrease heparanase expression and/or inhibit heparanase enzymatic activity in cancer cells significantly reduce their metastatic properties, signifying the importance of heparanase in cancer cell spread. Interestingly, no significant similarity or homology was observed between the human and murine heparanase sequences and any other reported protein. ${ }^{22,23}$ This suggests that cancer cells use a single heparanase to degrade heparan sulfate, and if its activity can be blocked, there may be no other enzymes to compensate for its absence. If confirmed, heparanase may be an attractive target for drug development relating to metastasis.

In conclusion, laser capture microdissection coupled with RT-PCR was a more reliable method for molecular analysis of heparanase gene expression in stomach tissue than direct RT-PCR from bulk tissue. Our study demonstrated that the expression of heparanase correlated with the biological behavior markers of gastric carcinoma, including depth of invasion and macroscopic classification. Finally, we found a high expression rate of heparanase in primary and metastatic gastric carcinoma, suggesting the crucial role of heparanase in gastric carcinoma cell invasion and metastasis.

\section{Acknowledgements}

This work was supported by the National 973 Program (No. G1998051203), the National Science Fund for Distinguished Young Scholars (No. 30125017), and the MOE TRAPOYT Program (No. 1999-96) of China.

\section{References}

1 Eccles SA. Heparanase: breaking down barriers in tumors. Nat Med 1999;5:735-736.

2 Iozzo RV. Matrix proteoglycans: from molecular design to cellular function. Annu Rev Biochem 1998;67: 609-652.

3 Bernfield M, Gotte M, Park PW, et al. Functions of cell surface heparan sulfate proteoglycans. Annu Rev Biochem 1999;68:729-777.

4 Emmert-Buck MR, Bonner RF, Smith PD, et al. Laser capture microdissection. Science 1996;274:998-1001.

5 Japanese Gastric Cancer Association. Japanese classification of gastric carcinoma-2nd English edition. Gastric Cancer 1998;1:10-24.

6 Sobin LH, Wittekind CH, TNM classification of malignant tumors, 5th edn. International Union Against Cancer (UICC). Wiley-Liss: New York, 1997, pp 59-62.

7 http://dir.niehs.nih.gov/dirlep/lcm/protocols.html.

8 Vlodavsky I, Friedmann Y. Molecular properties and involvement of heparanase in cancer metastasis and angiogenesis. J Clin Invest 2001;108:341-347.

9 Parish CR, Freeman C, Hulett MD. Heparanase: a key enzyme involved in cell invasion. Biochim Biophys Acta 2001;1471:M99-M108.

10 Inoue H, Mimori K, Utsunomiya T, et al. Heparanase expression in clinical digestive malignancies. Oncol Rep 2001;8:539-542.

11 Tang W, Nakamura Y, Tsujimoto M, et al. Heparanase: a key enzyme in invasion and metastasis of gastric carcinoma. Mod Pathol 2002;15:593-598.

12 Takaoka M, Naomoto Y, Ohkawa T, et al. Heparanase expression correlates with invasion and poor prognosis in gastric cancers. Lab Invest 2003;83: 613-622.

13 Shiraishi N, Inomata M, Osawa N, et al. Early and late recurrence after gastrectomy for gastric carcinoma. Univariate and multivariate analyses. Cancer 2000;89: 255-261.

14 Hulett MD, Freeman C, Hamdorf BJ, et al. Cloning of mammalian heparanase, an important enzyme in tumor invasion and metastasis. Nat Med 1999;5: 803-809.

15 Vlodavsky I, Friedmann Y, Elkin M, et al. Mammalian heparanase: gene cloning, expression and function in tumor progression and metastasis. Nat Med 1999; 5:793-802.

16 Koliopanos A, Friess H, Kleeff J, et al. Heparanase expression in primary and metastatic pancreatic cancer. Cancer Res 2001;61:4655-4659.

17 El-Assal ON, Yamanoi A, Ono T, et al. The clinicopathological significance of heparanase and basic fibroblast growth factor expressions in hepatocellular carcinoma. Clin Cancer Res 2001;7: 1299-1305.

18 Miao HQ, Elkin M, Aingorn E, et al. Inhibition of heparanase activity and tumor metastasis by laminarin sulfate and synthetic phosphorothioate oligodeoxynucleotides. Int J Cancer 1999;83:424-431.

19 Mishima T, Murata J, Toyoshima M, et al. Inhibition of tumor invasion and metastasis by calcium spirulan (Ca-SP), a novel sulfated polysaccharide derived from a blue-green alga, Spirulina platensis. Clin Exp Metastasis 1998;16:541-550.

20 Coombe DR, Parish CR, Ramshaw IA, et al. Analysis of the inhibition of tumour metastasis by 
sulphated polysaccharides. Int J Cancer 1987;39: 82-88.

21 Parish CR, Freeman C, Brown KJ, et al. Identification of sulfated oligosaccharide-based inhibitors of tumor growth and metastasis using novel in vitro assays for angiogenesis and heparanase activity. Cancer Res 1999;59:3433-3441.
22 Kussie PH, Hulmes DL, Ludwig DL, et al. Cloning and functional expression of a human heparanase gene. Biochem Biophys Res Commun 1999;261: 183-187.

23 Toyoshima M, Nakajima M. Human heparanase. Purification, characterization, cloning, and expression. J Biol Chem 1999;274:24153-24160. 